\title{
EL CALENDARIO MUSULMÁN DEL MANCEBO DE ARÉVALO*
}

\author{
Luis F. Bernabé Pons \\ Universidad de Alicante
}

Quisiera, en este volumen de la revista Sharq Al-Andalus. Estudios Mudéjares y Moriscos que se dedica en homenaje al profes or Leonard P. Harvey, presentar un trabajo que puede confluir con dos de las principales líneas de investigación que éste ha mantenido con magisterio a lo largo de su vida científica: la producción escrita de los moriscos y la figura del Mancebo de Arévalo. Cuando en el desarrollo del Proyecto de Investigación "Concordancias léxicas lematizadas de la obra del Mancebo de Arévalo”, llevado a cabo por el Área de Estudios Árabes e Islámicos de la Universidad de Alicante, nos topamos con el texto inserto en el manuscrito aljamiado misceláneo LXXXII de la Real Academia de la Historia, que indudablemente sólo podía pertenecer a la pluma del Mancebo, inmediatamente se concibió la idea de editarloํ․ El propio profesor Harvey, que colaboró activamente en el Proyecto, participó del interés que ofrecía el texto, el cual nos dio la oportunidad de mantener con él en Alicante una serie de interesantísimas sesiones científicas.

Por este motivo parece apropiado, en este volumen de homenaje científico, editar y estudiar este calendario islámico que, a semejanza de otros existentes en el fondo de la literatura morisca, compuso el Mancebo de Arévalo en Aragón. Aunque de tamaño infinitamente menor que sus obras más conocidas y de temática más semejante a otros manuscritos aljamiados, la intervención del autor castellano lo dota de una personalidad particular, atractiva para quienes, desde los pioneros trabajos de L.P.

\footnotetext{
Este estudio se ha realizado en el marco del proyecto de investigación Edición digital de los textos en español de los mudéjares y moriscos y su contexto historiográfico, con la referencia BFF2002-02497, del Plan Nacional de Investigación Científica, Desarrollo e Innovación Tecnológica, cofinanciado con FEDER y concedido en el año 2002.

1. Ver presentaciones del manuscrito en: L. F. BERNABÉ, “Un tiempo para los moriscos: el calendario islámico del Mancebo de Arévalo”, en: M. J. Rubiera (coord.), Carlos V, los moriscos y el Islam, Madrid: Sociedad Estatal para la Conmemoración de los Centenarios de Felipe II y Carlos V, 2001, pp. 91-102; “ Un 'nuevo' texto del Mancebo de Arévalo”, Sharq Al-Andalus. Estudios Mudéjares y Moriscos, Alicante-Teruel, 14-15 (1997-1998) [2002], pp. 469-470
} 
Harvey $^{2}$, se han acercado a la obra de tan peculiar autor. Si bien el texto no nos ofrece ningún dato nuevo que nos aclare de forma definitiva algo más sobre personalidad tan elusiva, sí vuelve a incidir sobre algunos de los enigmas que la crítica más reciente ha planteado sobre el Mancebo, en especial acerca de su carácter -único realmente- de hombre que planea sobre las tres culturas hispánicas en el siglo XVI.

El calendario religioso liga al creyente de cualquier religión a una serie de pautas de comportamiento espiritual que van disp oniendo su vida a lo largo de los días, las semanas y los meses del año. La persona atraviesa así periódicamente un conjunto de ciclos que modulan sus relaciones con el Ser Supremo a través de distintos estados o disposiciones espirituales y los actos rituales que los simbolizan ${ }^{3}$. También es el calendario religioso un testimonio de la unión en el tiempo de la comunidad de creyentes: los meses y los días se revisten de recordatorios y conmemoraciones de vidas y hechos pretéritos que son importantes para el establecimiento de la fe y pueden servir como guía para los sentimientos espirituales. Se disp one así un fuerte nexo personal entre la vida presente y la historia de la creencia, entre el discurrir vital del hombre y su pertenencia a una comunidad forjada en un momento determinado, pero aquilatada en la historia de la humanidad.

El calendario lunar de los musulmanes fue instituido bajo la autoridad del segundo califa,

2. The literary culture of the moriscos (1492-1609): a study based on the extant mss. in Arabic and Aljamia, Oxford, 1958 [Tesis Doctoral Inédita]; «Yuse Banegas: un moro noble en Granada bajo los Reyes Católicos», Al-Andalus, XXI (1956), pp. 297-302; "Un manuscrito aljamiado en la Biblioteca de la Universidad de Cambridge», Al-Andalus, XXIII (1958), pp. 49-74; «Amaḥo, dešamaḥo, maḥo, amaḥar... a family of words common to the Spanish speech of the Jews and of the Moriscos», Bulletin of Hispanic Studies, Liverpool, XXXVII (1960), pp. 69-74; «Castilian ' mancebo' as a calque of arabic 'abd, or how el mancebo de Arévalo got his name», Modern Philology, LXV (1967), pp. 130-132; «El mancebo de Arévalo y la tradición cultural de los moriscos», en: Actas del Coloquio Internacional sobre Literatura Aljamiada y Morisca, Madrid, 1978, pp. 20-41; "'The Thirteen Articles of the faith' and 'The Twelve Degrees in which the World is governed': Two Passages in a sixteeth-century Morisco Manuscript and their Antecedents», en: F. W. Hodcroft et al. (eds.), Medieval and Renaissance Studies on Spain and Portugal in honour of P. E. Russell, Oxford, 1981, pp. 15-29; «In Granada under the Catholic Monarchs: A call from a doctor and another from a 'curandera'», en: A. DEYERMOND \& I. MACPHERSON (eds.), Bulletin of Hispanic Studies, Special Issue. The Age of the Catholic Monarchs 1477-1516: literary studies in memory of Keith Whinnom, Liverpool, Liverpool University Press, 1989, pp 71-75; «El alfaquí de Cadrete, Baray de Reminjo y El Breve Compendio de Nuestra Santa Ley y Sunna», II Jornadas Internacionales de Cultura Islámica. »Aragón vive su historia» (Teruel, 1988), Madrid, Ed s. Al-Fadila (Instituto Occidental de Cultura Islámica), 1990, pp. 213-222; "El Mancebo de Arévalo and his treatises on Islamic Faith and Practice», Journal of Islamic Studies, 10:3 (1999), pp. 249-276.

3. M. de Epalza, “L'Is lam de sermpre”, en: M. de Epalza (dir.) - Equip CIDOB, L'Islam d'avui, de demà i de sempre, Barcelona, 1994, pp. 26-32. 
'Umar ibn al-Jat țāb (592-644 A.D.) ${ }^{4}$, para intentar acabar con los distintos sistemas de fechación, a veces divergentes entre sí, que existían en la época en la Península Arábiga, y, esp ecialmente, para tomar distancias del calendario luni-solar utilizado p or los antiguos árabes ${ }^{5}$. La necesidad de fijar definitivamente la fecha de la peregrinación a La Meca y de establecer un ritmo regular de acontecimientos importantes, establecidos por Dios, en el sentimiento religioso de los creyentes -obviando así la antigua costumbre preislámica, relacionada con la peregrinación, de la intercalación periódica de un mes - era y a patente en el texto coránico:

Te preguntan acerca de los novilunios. Di: "Son indicaciones que sirven a los hombres para fijar la época de la peregrinación”. La piedad no estriba en que entréis en casa por detrás, sino en que temáis a Alá $(\mathrm{Q} 2,189)^{7}$

El número de meses, para Alá, es de doce. Fueron inscritos en la Escritura de Alá el día que creó los cielos y la tierra. De ellos, cuatro son sagrados: ésa es la religión verdadera. ¡No seáis injustos con vosotros mismos no respetándolos! ¡Y combatid todos contra los asociadores como ellos también combaten todos contra vosotros! Y sabed que Alá está con los que le temen. (Q 9, 36)

El mes intercalar no significa más que un incremento en la incredulidad, con la que se extravían los infieles. Lo declaran profano un año y sagrado otro año, para estar de acuerdo con el número de lo que Alá ha declarado sagrado, declarando así profano lo que Alá ha declarado sagrado. La malicia de sus obras ha sido engalanada, pero Alá no dirige al pueblo infiel (Q 9, 37)

4. Existe una tradición, puesta bajo la autoridad de Ibn Šihāb az-Zuhrī, que atribuye al mismo Profeta la instauración del calendario islámico una vez llegado a Medina. Se trata, sin embargo, de un hadiz considerado de poca fiabilidad por su débil cadena de autoridades. Las tradiciones más consolidadas están de acuerdo en otorgar a 'Umar ibn al-Jat.t.āb la responsabilidad en la instauración oficial del calendario hegiriano. Ver F. Rosenthal, A History of Muslim Historiography, Leiden, 1952, p. 309. El propio Rosenthal recoge la versión autorizada y pormenorizada que da as-Sajāwī (m. 902) en su Al-I'lān bi-l-Tawbij li-man damma ahl al-tawrij (ibid. pp. 201-450).

5. M. OCAÑA JiMÉNEZ, Nuevas tablas de conversión de datas islámicas a cristianas y viceversa, Madrid, 1981, pp. 27-50.

6. Ver “Nasī'”, Encyclopédie de l’Islam, deuxième édition, Leyden-París, vol. VIII, 1993, 977-978 (en adelante será citada como E.I. ${ }^{2}$ ).

7. Cfr. Q 10, 5: “Él es Quien ha hecho del sol claridad y de la luna luz, Quien ha determinado las fases de ésta para que sepáis el número de años y el cómputo. Alá no ha creado esto sino con un fin. Él explica los signos a gente que sabe”. Todas las citas coránicas se refieren a la traducción efectuada por Julio Cortés. 
La necesidad de un cómputo estable de fechas se hizo patente para la naciente administración islámica, que veía en la revelación hecha al Profeta la inauguración de una nueva y fundamental era en la historia de la humanidad, pero que se encontraba con el problema de la falta de fijación cronológica tanto del propio acontecer del surgimiento del islam como de toda la doctrina que emergía de su propio seno. De esta forma, siguiendo las instrucciones de 'Umar, fueron seleccionados diversos nombres de entre los existentes previamente para los meses en la

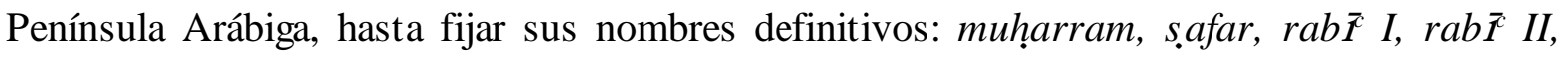
ŷumādà I, ŷumādà II, ra ŷab, šacbān, ramadiān, šawwāl, $\underline{\text { su}} \bar{u}-l-q a^{c} d a, \underline{d} \bar{u}-l-h i ̣ \hat{y} \hat{y} a^{8}$.

Junto a la cuestión de la nominación de los meses lunares existía la evidente cuestión de poner un inicio a la era islámica como jalón de inicio del triunfo del verdadero mensaje de Dios. Fue también decisión de 'Umar el establecer la migración (hi ŷra) de Muḥammad de La Meca a Medina como fecha de inicio del calendario musulmán. Fechas que podrían ser de muy esp ecial significación para los musulmanes, como la del nacimiento del Profeta o la del descenso de la primera revelación, no eran conocidas con exactitud, mientras que recurrir a la fecha de su muerte no parecía adecuado p or tratarse de un hecho enormemente triste para la comunidad de creyentes. La adopción de la fecha de la hégira de Muhammad como inicio del calendario islámico (16 julio 622 A.D. = 1 Muḥarram 1 A.H.) portaba una profunda carga conceptual -religiosa y política- para los creyentes: por un lado, se eliminaba cualquier posible semejanza con las conmemoraciones cristianas en torno al nacimiento y muerte del Jesús glorificado; por otro, se acentuaba el carácter comunitario del hecho fundacional de la datación musulmana, protagonizado por el Profeta de Qurayš, pero también por su pequeña comunidad de fieles. Finalmente, la hégira marcaba también el inicio del triunfo de la Revelación: la marcha desde La Meca a Medina, ese aparente fracaso de su misión, representa para los musulmanes el sacrificio p or la causa de la Verdad y por el establecimiento del mensaje divino.

Aunque los materiales judíos y cristianos eran abundantes y conocidos en la Península Arábiga desde mucho tiempo atrás, el islam hace incorporar al musulmán la historia común de la Revelación de la escritura divina que comparte con judíos y cristianos. Contemp lada y concep tuada desde la visión prop ia del profetismo mahomético, la historia de judíos y cristianos es también la historia del islam y, naturalmente, la historia de la humanidad es asimismo la historia islámica. Más allá de las averiguaciones acerca del material doctrinal que Muhammad pudo haber tomado de judíos y cristianos, algo que, dicho sea de paso, resulta particularmente inútil y ofensivo para muchos musulmanes ${ }^{9}$, lo que importa retener es que el islam también se

8. E. LitTMAn, “Die Ehrennamen und Neubenennungen der islamische Monate”, Islami ca, VIII (1918), pp. 228-243.

9. Ver R. Totтoli, “Nota su una moderna posizione critica nei confronti delle Isrā'iliyyāt”, Oriente Moderno, 70 (1990), pp. 115-118; Id. “La moderna esegesi islamica ed il rifiuto delle isrā' 1 liyyāt: le leggende sul bastone di Mosè mutato in serpente”, Annali di Cà Foscari, 21 (1990), pp. 25-35. 
reconoce en las grandes figuras del judaísmo y del cristianismo y de sus vidas saca numerosos ejemplos de virtud y de meditación ${ }^{10}$.

De esta manera, al lado del contenido religioso estrictamente islámico que fueron adquiriendo estos meses (peregrinación, ayunos, efemérides relacionadas con el Profeta, etc.) éstos fueron llenándose asimismo de recordatorios de una figura o de una acción del pasado judío o cristiano que servía de norma y modelo piadosos. Abraham, José, Noé, Jesús o el mismo Alejandro Magno islamizado se convierten en ejemplo y vía de reflexión para los musulmanes merced a su inclusión en una fecha del calendario. Junto a su naturaleza ejemplar, estos recordatorios, de plena integración en la visión islámica del tiempo, proporcionan el necesario sustrato "histórico" de diversas conmemoraciones y ceremonias islámicas.

Se articula, entonces, el calendario musulmán como un sistema de tiempo con tres niveles simultáneos: histórico, religioso y sentimental. Histórico porque comienza a partir de un acontecimiento determinado que cambiará el destino de los fieles; histórico asimismo porque fue creado por unas personas concretas en un tiempo y lugar determinados; e histórico finalmente porque diversos acontecimientos de la vida de Muhammad y del triunfo del islam se reconocen en su colocación dentro de días especialmente señalados del año musulmán. Tiene lógicamente también un importante nivel religioso en tanto en cuanto es un calendario realizado sobre un mensaje religioso que quiere desterrar creencias antiguas y en tanto en cuanto se construye a partir de un mandato coránico. Este carácter religioso queda fijado de forma muy especial por las obligaciones o recomendaciones piadosas que el islam fija para distintos días de diferentes meses: ayunos, oraciones concretas, limosnas... son los jalones de piedad que marcan regularmente el año para el creyente como modo idóneo de cumplir con la voluntad de Dios. El calendario regula así los distintos niveles de lo sagrado para el ser humano en su acción cotidiana y también las diferentes enseñanzas religiosas que puede sacar de la historia espiritual de la humanidad.

Finalmente también se configura el calendario musulmán desde un vector sentimental. El calendario lunar recuerda y es testimonio del sacrificio del Profeta por mor del triunfo final de la religión: los sentimientos de los creyentes se articulan a través de la percepción de ese fracaso en el inicio del año para ir mutando progresivamente hasta llegar, en el último mes del año, a la exposición espiritual plena a Dios por parte del creyente. Los acontecimientos más remarcables de la primera historia del islam, situados a lo largo del año, se encajan asimismo dentro de este nivel sentimental: las conmemoraciones de las distintas batallas contra los infieles van llenando de alegría y coraje los corazones de los creyentes; el recordatorio de los milagros realizados por el Profeta con el permiso de Dios llenan de reverencia las almas de los

10. Véase, a mero título de ejemplo relacionado con los mori scos, en una bibliografía oceánica, M. de EpALZA, Jesús entre judíos, cristianos y musulmanes hispanos ( s iglos VI-XVII), Granada, 2001; A. VeSPERTINO RODRÍGUEZ, Leyendas aljamiadas y moriscas sobre personajes bíblicos, Madrid, 1983. 
musulmanes. Aunque puede utilizarse el calendario solar u occidental, el creyente islámico se reconoce sentimentalmente en esta cronología religiosa y reconoce a los que participan también de ella. El calendario hegiriano, como uno de los más imp ort antes exponentes de una vida islámica, es un elemento fundamental de cohesión, siquiera sentimental, de la comunidad universal de crey entes islámicos.

\section{LOS CALENDARIOS MORISCOS}

Desde este punto de vista, no resulta especialmente extraño, entonces, el que dentro del fondo de literatura aljamiada atesorado por los moriscos se encuentren no escasas muestras de calendarios islámicos que van explicando de forma paulatina las obligaciones y las conmemoraciones que afectan a la vida del musulmán. La situación social, política y religiosa a la que había llegado la comunidad morisca aragonesa o castellana se basta por sí sola ${ }^{11}$ para exp licar la aparición múltip le de estos calendarios: constreñidos a la instrucción y manifestación pública de la fe cristiana, aculturados desde hacía tiempo en su may oría en la lengua árabe y alejados de cualquier estructura normal de enseñanza religiosa islámica, los mudéjares primero y los moriscos después necesitan del escaso acervo islámico en castellano que van atesorando en sus papeles generación tras generación ${ }^{12}$. Envueltos por el calendario y las solemnidades cristianas, los moriscos necesitan sus propias pautas cronológicas para asumir su visión sagrada del tiemp o y para cumplir con el deber de unos actos religiosos que los vinculan al Där al-Isläm.

Los calendarios islámicos que poseían los moriscos y que han llegado hasta nosotros cumplen perfectamente con este pap el de diap asón de una vida correcta como crey entes: yendo mes tras mes o fijándose en un mes o incluso un día concretos, van desgranando con precisión y regularidad cuáles son las oraciones, actos o recuerdos que cada día contempla desde la óp tica islámica ${ }^{13}$. La ruta de los tiempos esp ecialmente sacros es también marcada en estos calendarios: existen días y noches de mayor “alfadila” (al-faḍila = virtud, mérito, entorno espiritual favorable) en los que las oraciones o los ayunos tienen incomparablemente may or valor como corresponde a su muy especial naturaleza. Los esfuerzos piadosos, muchas veces de difícil práctica para los moriscos ${ }^{14}$, quedan encuadrados de esta manera en una visión islámica de la

11. Míkel de Epalza, Los moriscos antes y después de la expulsión,, Madrid, 1992, pp. 101-118.

12. Luis F. Bernabé Pons - María Jesús Rubiera Mata, “ La lengua de mudéjares y moriscos. Estado de la cuestión”, Actas del VII Simposio Internacional de Mudejarismo, Teruel, 1999, pp. 599-631.

13. Ver Pedro LongÁs, La vida religiosa de los moriscos, Madrid, 1915; nueva edición facsímil Granada, 1990, especialmente pp. 19, 74, 90-98, 29-230.

14. Ver L. P. Harvey, “Los moriscos y los cinco pilares del Islam”, en: Abdeljelil Temimi (ed.), Las prácticas musulmanas de los moriscos andaluces (1492-1609). Actas del III Simposio Internacional de Estudios Moriscos, Zaghouan, CEROMDI, 1989, pp. 93-97. 
existencia, que promete al que persevera en su fe, al verdadero guerrero en el islam, la recompensa final a la suma de todos sus méritos.

Los textos moriscos que contienen calendarios o instrucciones sobre alguna fecha particular son los siguientes ${ }^{15}$ :

1) British Museum Ms. Or. 6640. Dado a conocer por L. P. Harvey ${ }^{16}$, contiene algunas azoras coránicas en árabe y diversos apartados sobre doctrina islámica, en árabe o aljamiados. Entre los folios 96r. y 106r. se encuentran "los nombres de las lunas por el cuento de los muslimes”, que fue editado asimismo por el Prof. Harvey ${ }^{17}$.

2) Archivo Diocesano de Cuenca, Inquisición, legajo 237, n. ${ }^{\circ}$ 3072. Se trata de dos cuadernillos cosidos que se incluyeron en el proceso inquisitorial del morisco Jerónimo Pintor. Junto con otros fragmentos ${ }^{18}$, el manuscrito contiene (ff. 1-10) un calendario lunar que comienza no en Muharram, sino en Ramaḍan, atravesando el año hasta completar todos los meses. Fue editado también por Harvey, junto con el manuscrito anterior ${ }^{19}$.

3) Manuscrito J XXVIII del Instituto Miguel Asín del Consejo Superior de Investigaciones Científicas (antes Junta para Ampliación de Estudios e Investigaciones Científicas) ${ }^{20}$. Manuscrito misceláneo muy bien conservado y de letra muy clara, con copia de diversas azoras coránicas más diversos preceptos religiosos aljamiados. En los folios 114v. -141v. se encuentra "el regimiento de las lunas y el cuento dellas para los muslimes”.

15. Recientemente, en Aljamía, 15 (2003), pp. 85-89, G. Wiegers ha dado noticia de un manuscrito aljamiado existente en la Biblioteca Nacional de Malta que contiene en su primera parte "una relación de los meses con indicación de señalados días festivos”, entre los folios 253r y 249v (la foliación del manuscrito, como señala Wiegers, es moderna y occidental, por lo que el manuscrito está foliado al revés).

16. “A Morisco Prayer-Book in the Bristish Museum: Ms. Or. 6640. Press Mark: 30, B.A.”, Al-Andalus, XXIX, 2 (1964), pp. 373-376.

17. “The Terminology of Two Hitherto Unpublished Morisco Calendar Texts”, en: A. Temimi (ed.), Actes de la première Table Ronde du C.I.E.M. sur: La littérature aljamiado-morisque: hybridisme linguistique et univers discursif, Túnez, 1986, pp.65-83.

18. Ver L. P. HARVeY, “ La leyenda morisca de Ibrahim”, Nueva Revista de Filología Hispánica, XXX (1981), pp. 1-20.

19. “The Terminology”, pp. 67-73.

20. Julián Ribera - Miguel Asín, Manuscritos árabes y aljamiados de la Biblioteca de la Junta, Madrid, 1912, p.118. A partir de esta cita, se entiende que todos los manuscritos cuya signatura comienza por J [= Junta] pertenecen al mismo fondo sito en el CSIC, por lo que no se repetirá la localización en cada uno de ellos. 
4) Manuscrito J LV del mismo Instituto ${ }^{21}$. Manuscrito misceláneo con narraciones piadosas e instrucciones rituales aljamiadas. Incluye, entre los folios 59r. y 72 v., un calendario islámico con explicación de conmemoraciones y ceremonias religiosas. En los folios 73v.-74r. se encuentra un listado en árabe de los nombres de los doce meses.

5) Manuscrito $\mathrm{J} \mathrm{LX}^{22}$. Manuscrito en caracteres latinos que contiene diversas materias, fundamentalmente hadices piadosos y el Breviario sunní de 'Īsā de Gebir. Entre los folios 14 y 170 puede leerse, aunque en páginas manchadas y traspasadas de tinta, un “regimiento de las lunas de todo (e)l año, dy as alfadilosos y de dayuno y lo que se a de açer en ellos de alibeda y todos los qunplimientos que qualquiere buen muçilim debe açer en ellas”.

6) Manuscrito 505 de la Biblioteca Provincial de Toledo ${ }^{23}$. Manuscrito aljamiado de tema piadoso que contiene una primera parte de castigos (was.aya), atribuidos a Muqātil ibn Sulaymān, seguida de una serie de instrucciones prácticas sobre ceremonias islámicas. En los folios 36r. a 45v. “comiençan los nonbres de las lunas en arabí”, que se comparan con los nombres cristianos, detallándose todas las conmemoraciones de cada fecha.

7) Manuscrito 5354 de la Biblioteca Nacional de Madrid ${ }^{24}$. Contiene, junto con las mil doscientas sentencias del Profeta, de Abū cAbd Allāh al-Qudā'i, una relación de las virtudes de las oraciones que se realizan cada uno de los días de las semanas $\mathrm{y}$, en los últimos 15 folios, un calendario lunar, semejante al anterior.

8) Manuscrito 5374 de la Biblioteca Nacional de Madrid ${ }^{25}$. Manuscrito aljamiado de instrucciones para llevar a cabo diversas prácticas is lámicas, que contiene entre los folios 19r. y 21 r. los nombres de las lunas.

9) Manuscrito 6016 de la Biblioteca Nacional de Madrid ${ }^{26}$. Caracteres latinos. De contenido similar al número 5) de esta relación, aunque difieren en algunas partes, con tiene en su parte final un "regimiento de las doze lunas del año y de los dias alfadilossos, de dayuno y açalaes”.

21. Ibid., pp. 200-201.

22. Ibid., p. 215.

23. Ver Ángel GonzÁlez Palencia, “Noticias y extractos de algunos manuscritos árabes y aljamiados de Toledo y Madrid”, Miscelánea de Estudios y Textos Árabes, Madrid, 1915, pp. 115-145.

24. SAAVEDRA, p. 135.

25. Ibid., p. 137.

26. Ibid., p. 105. 
10) Manuscrito de la Biblioteca Nacional de París $1163^{27}$, misceláneo aljamiado de narraciones piadosas e instrucciones doctrinales y rituales que contiene, entre sus folios 158fv. - 170r. las ventajas espirituales y ceremoniales de cada uno de los meses del año.

11) Manuscrito XIII de la Real Academia de la Historia ${ }^{28}$. Texto fundamentalmente doctrinal, con una única narración protagonizada por Moisés, que contiene entre los folios 94r. a 115r un calendario islámico.

Al lado de estos calendarios hegirianos completos, los manuscritos moriscos también conservan otros calendarios que no recogen el ciclo lunar anual, bien porque se presentan de manera fragmentaria, bien porque el texto en cuestión ha preferido centrarse sobre las ceremonias, ventajas y fiestas de un mes o un día concretos, generalmente los de mayor significación o contenido sacros ${ }^{29}$ :

1) Manuscrito A de la Biblioteca del Colegio de los Padres Escolapios de Zaragoza $^{30}$. Manuscrito aljamiado que contiene una colección de jut bas para los viernes, una serie de tradiciones, exhortaciones y oraciones, así como (ff. 228v. - 304v.) una larga explicación acerca de las fiestas, conmemoraciones y ceremonias obligatorias y devocionales que existen en los meses de Raŷab, Šacban y Ramaḍān.

27. Ibid.pp. 145-147

28. Álvaro Galmés DE FuENTEs, Los manuscritos aljamiado-moriscos de la Biblioteca de la Real Academia de la Historia (Legado Pascual de Gayangos), Madrid, 1998, pp. 73-75, con la bibliografía allí citada. Como puede comprobarse, utilizo, con vistas a una necesari a homogeneización, la numeración que otorga Galmés de Fuentes en su reciente catálogo a los manuscritos del legado de Gayangos en la Real Academia de la Historia, en lugar de la más extendida -desde el catálogo de Saavedra- que dividía a dichos manuscritos en las series S, Ty V.

29. Existen otros textos que guardan relación, más o menos estrecha, con la distribución de los tiempos especialmente favorables para el creyente a lo largo del año. Se trata de textos acerca de los días propicios $\left(s a^{c} d\right)$ o nefastos (naḥs) para el musulmán, en la semana, en el mes o a lo largo del año -islámico u occidental-, de textos sobre el cálculo de aparición de la luna de un mes a lo largo de diversos años, de las ju t bas apropiadas para días determinados de los meses, etc. Al no tratarse sensu stricto de exposiciones cronológicas ordenadas como las que nos ocupan, no aparecen en ninguna de las dos listas que se ofrecen. Puede verse, como ejemplo de estos textos, R. SuÁREZ PiÑERA, “ Días fastos y nefastos en las creencias de los muslimes”, Actas del Coloquio Internacional sobre Literatura Aljamiada y Morisca (Oviedo, 1972), Madrid, 1978, pp. 165-186 y T. Fuente Cornejo, “Las anotaciones en caracteres latinos de las guardas del ms. aljamiado-morisco J XIII”, Sharq Al-Andalus. Estudios Árabes, Alicante, 8 (1991), pp. 137-152. 
2) Manuscrito $\mathrm{J} \mathrm{VIII}^{31}$. Voluminoso manuscrito piadoso en el que se recogen elementos doctrinales y narraciones devotas islámicos. Entre los diversos capítulos se recogen las “alfadilas” de la noche de lay lat al-qadr, de los diez días “de la alhache de pascua de carneros” y del día de cašūra’.

3) Manuscrito $\mathrm{J} \mathrm{IX}^{32}$. De contenido similar al anterior, auque con una mayor presencia de las narraciones piadosas, el texto desarrolla las virtudes piadosas que poseen diferentes días. Así, entre los folios 133r. y 147v. se va pasando cuenta de la “alfadila” del mes de Raŷab, Šacban y Ramaḍan, así como de la noche de laylat al-qadr y de los diez días de Pascua.

4) Manuscrito J XXXVII, que contiene una descripción de las ceremonias y conmemoraciones de la luna de Muḥarram ${ }^{33}$ en los folios 35v. a $37 \mathrm{r}$.

5) Manuscrito J LVII, que desarrolla a lo largo de los folios 95v. - 98r. las virtudes del ayuno mantenido en el mes de Raŷab ${ }^{34}$.

6) Manuscrito de la Biblioteca Nacional de París 744, misceláneo aljamiado que contiene una breve noticia de los meses y fiestas musulmanes (ff. 206r. - 209v.). ${ }^{35}$

7) Manuscrito aljamiado-morisco I de la Real Academia de la Historia ${ }^{36}$. Texto en caracteres latinos que contiene tres capítulos sobre los premios del ayuno del día de cašūra’, de la oración en la noche a mitad del mes de Šacban y de la oración en la noche vigésimo novena del mismo mes (ff. 65-67).

8) Manuscrito RAH IX ${ }^{37}$. Manuscrito acéfalo que contiene, desde el princip io hasta el folio 34v. la parte final de un calendario lunar, abarcando cinco de los meses del año.

9) Manuscrito RAH XVIII ${ }^{38}$. Misceláneo aljamiado que entre los folios 154r.- 165r. desarrolla las virtudes de las lunas de Raŷab y Šacban, mientras que en los folios 207v. a 213r. se centra en el mes de Ramaḍan.

\footnotetext{
31. Ibid., pp. 44-45.

32. Ibid., pp. 51-52.

33. Ibid., pp. 137-140.

34. Ibid., pp. 200-201.

35. SAAVEDRA, p. 143.

36. GALMÉS DE FUENTES, pp. 11-16.

37. Ibid., p. 65 .

38. Ibid., pp.91-96.
} 
10) Manuscrito RAH XXIII ${ }^{39}$, que contiene fundamentalmente una versión del Kitab al-anwār de al-Bakrī, conserva asimismo la última página de una relación de las lunas del año.

11) Manuscrito RAH XXV $\mathrm{XV}^{40}$. Manuscrito misceláneo de tipo ejemplar que, según indica Galmés de Fuentes, contiene de forma fragmentada una relación de las lunas del año “por el cuento de los muslimes” en los folios 20v. - 21v. y 92r. 97r.

\section{EL CALENDARIO DEL MANCEBO DE ARÉVALO}

Como ya se ha señalado, el manuscrito XIII de la Real Academia de la Historia contiene hacia su mitad un calendario hegiriano con unas características particulares. Dicho manuscrito fue ya descrito por E. Saavedra en el "Indice general de la literatura aljamiada"41 que formaba el apéndice I de su Discurso de ingreso en la Real Academia Española. Con el número LXXXII (Biblioteca de D. Pascual de Gay angos T. 8), el benemérito arabista daba noticia del manuscrito, procedente de la venta de Conde. Según Saavedra, el texto tenía "letra y papel del siglo XVI, idénticos á los del Mancebo de Arévalo, con cuyo libro estuvo en poder del mismo sujeto que anotó al margen algunas palabras”42, pasando después a describir los contenidos del manuscrito. El catálogo moderno de Galmés de Fuentes, que ofrece, naturalmente, mucha más información que el índice de Saavedra, nos aclara que la referencia -algo confusa- de Saavedra se refiere a que la letra magrebí del manuscrito de la Real Academia de la Historia es idéntica a la del manuscrito Res 245 de la Biblioteca Nacional de Madrid. Este texto, copiado entonces por el mismo copista, contiene, como es sabido, el Sumario de la Relación y ejercicio espiritual, la obra más espiritualist a del Mancebo de Arévalo, en la que copia, convenientemente adaptado, la Imitación de Cristo de Tomás de Kempis, como descubriera en su tiempo Gregorio Fonseca Antuña en su tesis doctoral ${ }^{43}$. No parece sin embargo, a priori, nada especialmente significativo el que ambos manuscritos hay an pasado por las manos del mismo copista, dada la diferencia de letra con los otros dos largos textos del Mancebo, los contenidos en el manuscrito de Cambridge

39. Ibid., pp. 105-112.

40. Ibid., pp. 121-129.

41. SAAVEDRA, pp. 103-181.

42. Ibid., p. 160.

43. G. FonSECA ANTUÑA, "Sumario de la relación y ejercicio espiritual sacado y declarado por el Mancebo de Arévalo" (Ed. y estudio del ms. B.N.M. Res 245), Oviedo, 1987. Véase ahora la edición en Madrid, Fundación Menéndez P idal, 2002. Ver también, en la misma y trascendental línea, María Teresa NARVÁEz, “El Mancebo de Arévalo, lector morisco de La Celestina”, Bulletin of Hispanic Studies, LXII (1995), pp. 255-272. 
y en la Tafs $\bar{T} a^{44}$, manuscrito LXII de la Biblioteca del Instituto Miguel Asín.

El texto del Mancebo de Arévalo que contiene el calendario lunar islámico presenta la misma ordenación y estructura que los otros calendarios moriscos: orden de los meses, especificación de días importantes dentro de esos meses, indicación de oraciones y esfuerzos piadosos que resulta ventajoso realizar en esas fechas y hechos o vidas memorables que se conmemoran en esos días o noches. Estos últimos, las indicaciones rituales y los recordatorios de hechos señalados, tampoco se apartan demasiado de lo que es habitual en estos textos, lógicamente caracterizados por un rígido normativismo. No es exactamente el contenido lo que especifica al texto, sino la mano que ha tomado ese contenido normativo y tradicional y ha introducido dentro de él expresiones, figuras o ideas completamente singulares dentro del acervo de la literatura aljamiada. La Mora de Úbeda o 'Umar Bey, el šubelar o la prestamança, son algunos de los elementos conocidos y rabiosamente personales del Mancebo de Arévalo que aparecen también en este texto y que lo dotan -sensación ya familiar- de una desconcertante originalidad.

El año islámico comienza por el mes de al-muharram, que marca el inicio sagrado del ciclo lunar y cuy o nombre era en principio un adjetivo de s.afar, nombre con el que comenzaban los dos primeros meses del año en ép oca preislámica ${ }^{45}$. Dos son los vectores fundamentales que va recorriendo el texto del Mancebo: la señalización de los días especialmente indicados para la piedad y los hechos que se conmemoran tales días y que proporcionan las razones "históricas" para la consideración de dichos días. No es de extrañar, por tanto, que la primera mención sea para la propia fuente del calendario lunar musulmán, la hégira de Muḥammad, solemnización -indica el Mancebo- de cualquier tipo de peregrinación.

Los días de especial devoción dentro del mes de al-muḥarram son el primero; tercero (uno de los siete días más señalados del año); noveno, décimo y undécimo (Pascua de Atuse, según el Mancebo) ${ }^{46}$. El 10 de muhạrram queda naturalmente señalado por el ay uno de '⿳亠厶⿲̌šūā', el antiguo día de la expiación judía ${ }^{47}$, que, sin resultar obligatorio para los musulmanes como el de Ramaḍān, queda como un esfuerzo libre de alta piedad. Es este día el que acumula tras de sí

44. Editada en la tesis doctoral de la profesora María Teresa Narváez (Puerto Rico, 1983), está anunciada su aparición para el presente año 2003 por parte de la editorial Trotta.

45. “ “al-Muh arram”, E.I. ${ }^{2}$, vol. VII, 1993 (M. P LESSNER).

46. En realidad Tās $\bar{u}^{\mathrm{c}} \overline{\mathrm{a}}$ ' designa al ayuno no obligatorio que se realiza el 9 ó 10 de Muharram, o bien ambos días, que algunos instituyeron para diferenciarse de la herencia judía que suponía el ayuno de c $\bar{A}$ šū $\overline{\text { ā' }}$. Ver “c $\bar{A} \operatorname{shū}$ ā”, E.I. ${ }^{2}$, vol. I, 1960 (A.J. WENSINCK).

47. Ibid. Cfr. Levítico, XVI, 29-30: “Esta será para vosotros ley perpetua; el séptimo mes, el día diez del mes, mortificaréis vuestras personas y no haréis trabajo alguno, ni el indígena ni el extranjero que habita en medio de vosotros; porque en es e día se hará la expiación por vosotros para que os purifiquéis y seáis purificados ante Yavé de todos vuestros pecados”. 
una auténtica plétora de acontecimientos importantes (desde la propia creación del mundo) que justifican su importancia como uno de los más señalados del año lunar. Los días trece, catorce y quince de la luna entran también dentro de la categoría de días especiales, puesto que el ecuador de cada mes lunar es un período de especial gracia para quien realiza cualquier tipo de esfuerzo piadoso.

No hay, pues, grandes novedades en lo que se refiere a las ceremonias, oraciones y ay unos que el crey ente puede realizar en esta luna, así como en las conmemoraciones que pueden recordarse en Muharram: la lectura de otros manuscritos que contienen calendarios no hace sino confirmar la presencia de estos mismos elementos, como, por otra parte, sucede con el resto de los meses. Sí que aparecen, sin embargo, elementos nuevos que singularizan a este texto: es sorprendente, por ejemplo, la aparición del coránico Qārūn, el judío bíblico Coré que dirigió una sedición contra Moisés ${ }^{48}$ y que en el Corán se aparta del pueblo de Moisés envanecido por su proverbial riqueza y por su ciencia ${ }^{49}$. En el texto del Mancebo Qārūn ap arece como un sabio que parece comentar con solemnidad el hecho de la peregrinación de Muḥammad:

Y dixo el sabio de los judíos que se decía Karūn: “ oy nos á señalado el Dio gran causa”

quizá haciendo referencia a su papel de conocedor de ciencias ocultas y de hechos futuros que sugiere el Corán y desarrollan los qișșas. al-anbiyā' y que y a se encontraba presente en la Agadá judía $^{50}$. Dejando aparte esta intervención profética, merece la pena destacarse, de nuevo en el Mancebo de Arévalo, la aparición de la forma Dio, específica de los judíos hispanos, para nominar a Dios y que parece implicar algo más que un conocimiento externo y superficial del judaísmo, como y a pusiera de manifiesto la profesora Rubiera Mata ${ }^{51}$.

Pero no es sólo la de Qārūn la aparición destacable del mes de al-muhạrram, puesto

48. Ver Números, XVI.

49. Ver Corán XXVIII, 76-82; XXIX, 39; XL, 24.

50. D. SIDERSKY, Les origines des légendes musulmanes dans le Coran et dans les vies des prophètes, París, 1933, pp. 95-97.

51. “Nuevas hipótesis sobre el Mancebo de Arévalo”, Sharq Al-Andalus. Estudios Mudéjares y Moriscos, 12 (1995), pp. 315-323, esp. pp. 321-322. No está de más señalar asimismo que el propio Mancebo declara que los innumerables acontecimientos que han tenido lugar el día de cāšūrā' ocupan bastante espacio "en las leciones arábigas y hebraicas”. Aún suponiendo que este último término hiciera simple referencia a las isră'iliyyāt (referencia técnica, en cualquier caso, bastante rara en la España del siglo XVI), basta recordar las frecuentes remisiones del Mancebo a los libros judíos que declara conocer o haber leído como para pensar, como propuso la profesora Rubiera, en una presencia del elemento judío de mucha más trascendencia de lo que se había venido pensando. Ver asimismo, de la misma autora, "El judeo-converso y moris co 'Mancebo de Arévalo', autor de las tres culturas hispánicas”, en: M. BERNARdinI, C. BorreLLI, A. CERbo, E. SÁnchez García (eds.), Eur opa e Islam tra i secoli XIV e XVI / Europe and Islam between 14 th and 16th centuries, Napoli, 2002, vol. II, pp. 839-856. 
que a su propósito aparecen dos de las “autoridades” más destacadas en los pasajes doctrinales de toda la obra del Mancebo de Arévalo: la Mora de Úbeda, anciana morisca que desempeñó algún papel en la corte nazarí y que vivía en tiemp os del Mancebo en la Puerta Elvira de Granada, y que siempre aparece como una rígida amonestadora del ligero saber islámico del autor castellano; y el todavía más incógnito `Umar Bey, seguramente marca de autor bajo la que deslizar cualquier pasaje doctrinal. La primera interviene en dos ocasiones, la primera de forma indirecta, al parecer confirmando unas palabras de 'Umar Bey (el dayunar estos días de al-muharram es obra santa), y la segunda, a propósito de que no basta con conocer y cumplir con los ritos de la religión para adquirir las bendiciones de Dios.

El segundo tiene dos intervenciones, mezcladas con las de la Mora de Úbeda, si bien en esta ocasión no destacan por su originalidad: en la primera se limita a comentar lo propicios que son los días medios de cada luna, y en la segunda exhorta a los crey entes a cumplir con los días “alfaḍilosos”, si no con el ayuno, sí al menos con algún tipo de acto piadoso y, especialmente, con el obrar bien.

Șafar, Rabī̄ ${ }^{\mathrm{al}}$-awwal, Rabīi ${ }^{\mathrm{c}}$ al-ajar, Ŷumādā al-awwal y Ŷumāda al-ajar, como en los demás calendarios moriscos, apenas tienen días de especial disposición espiritual; el primero (“luna de conquista”) es recordado por el Mancebo por la batalla de Badr, la primera y mítica victoria de los creyentes contra los infieles ${ }^{52}$; el duodécimo día de Rab̄̄ic I está especialmente presente en la vida de los musulmanes por ser el día que la tradición ha acordado para el nacimiento del Profeta Muḥammad, mientras que Rabī ${ }^{\mathrm{c}}$ II, excepto los días medios del mes, no tiene más conmemoración que el nacimiento de $\underline{\text { Du}} \mathbf{u}-\mathrm{l}-\mathrm{Q}$ arnayn.

Raŷab, el mes de Dios (šahr Allah) ${ }^{53}$, es la siguiente luna en la que el calendario del Mancebo se detiene de forma especial. Aunque el ay uno durante esta luna es tema de amplia discusión en la tradición islámica, ha quedado como una muy recomendable práctica piadosa, merecedora de amplias recompensas ${ }^{54}$. Y es que este mes está especialmente marcado por ser el tercer día -otro de los siete especiales del año- el de la revelación de la primera aley a del Corán y, por extensión, del descubrimiento del poder profético depositado en Muhammad. También el vigesimosép timo del mes de Raŷab es un día de especial faḍila, no sólo porque es superior incluso a liberar (alhurrar) a cautivos musulmanes, sino también porque 'Umar Bey de nuevo lo llega a colocar por encima de la peregrinación a La Meca.

Otra de las sorpresas del texto se abre en el mes de Raŷab con una particular referencia

52. M. GaUdefroy-DEMOMBYNES, Mahoma, Madrid, 1990, pp. 106-115.

53. M. J. KisteR, "Rajab is the Month of God. A Study in the Persistence of an Early Tradition”, Israel Oriental Studies, Tel Aviv, 1 (1971), pp. 191-223; reimpr. en Studies in Jăhiliyya and early Islam, Londres, Variorum, 1980, n. ${ }^{\circ}$ XII.

54. “Radjab”, E.I. ${ }^{2}$, vol. VIII, 1994 (M.J. Kister). 
a lo que parecen ser los șafawíes, precisamente a cuenta del 27 de este mes :

Esti dia facen los ŷafawíes grande solenidad por la bendición de un rey que fue muy dotomado, que nació tal día y fue de grande conquista

No sabemos casi nada acerca del nivel de conocimientos que en la España de la primera mitad del siglo XVI pudiera tenerse acerca de la historia y la realidad persas -y por eso cualquier mención en este sentido no deja de ser peculiar. Es precisamente a comienzos del siglo XVI, en 1501, cuando los șafawíes, encabezados por el joven y ambicioso Ismā'îl, van a establecer un Estado propio en Persia, dotándolo, después de ocho siglos y medio de conquista árabe, de una dinastía persa ${ }^{55}$. El mismo Ismā'̄̄l Šāh va a declarar a la šî́ca duodecimana como la religión oficial del Estado, distinguiéndose así del poderoso vecino otomano, de oficialidad sunní, y va a comenzar una activa política expansionista que se verá bruscamente frenada p or el ejército del sultán turco Selīm en la terrible derrota de Čāldirān ${ }^{56}$.

¿Es ese rey “dotomado” al que hace referencia el Mancebo de Arévalo el propio Ismā’īl Šāh? Lo cierto es que la cercanía de las fechas entre la muerte del gobernante persa (1524) y las fechas en las que el Mancebo de Arévalo desarrolla su actividad en Aragón (que podemos establecer con cierta seguridad en la década de los treinta del siglo XVI) p arecerían desaconsejar esa relación. Sin embargo, y sin pretender resolver la incógnita de manera definitiva, cabe señalar que, aparte de su impulso guerrero, Is mā' '̄l Šāh se identificaba, dentro del discurso religioso safawí, con Jesús, hijo de María, con diversos personajes épicos de la Persia legendaria y asimismo con el imām justo y perfecto ${ }^{57}$. Sin embargo su nacimiento tuvo lugar un 25 de Raŷab del año 892 de la Hégira, lo que quizá, aún teniendo en cuenta la pequeña variante de tiemp o que podría darse en el cambio de cómputo de fechas cristianas a fechas islámicas (nació un 17 de julio de 1487), invalidaría la propuesta.

Šacban, el mes del Profeta ${ }^{58}$, es brevemente recordado por el Mancebo de Arévalo en especial por la noche que antecede al decimoquinto día, en la que se recita la oración del bien ${ }^{59}$ y en la que cobra especial imp ortancia el estado de limpieza ritual. La noche del Tahor o noche

55. Ver José Francisco Cutillas FERRER, “El siglo XVI y el comienzo de las relaciones diplomáticas con Persia: Carlos V y Šăh Ismā̄īl”, en: M. J. RubieRA (coord.), Carlos V, los moriscos y el Islam, pp. 339-346.

56. “Ṣafawides”, E.I. ${ }^{2}$, VIII, 1995, 791-800 (R.M. SAVORY).

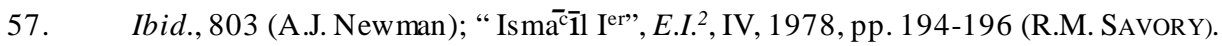

58. M.J. KISTER, “Šacban is my Month. A Study on Early Tradition”, Studia Orientalia Memoriae D.H. Baneth Dicata, Jerusalén, 1979, pp. 15-37.

59 Ver G.E. von GruneBaum, Muhammadan festivals, Londres-Ottawa, 1976 (r.), pp. 53-54. 
de la gracia dota de una especial bendición al día que le sigue, uno de los siete más especiales del año.

El mes de Ramaḍān, de profunda importancia para todo musulmán, es el mes del ayuno por antonomasia, para todo crey ente que esté legal, física y psíquicamente cap acitado para ello ${ }^{60}$. Luna de especial espiritualidad en el islam, los acontecimientos que se conmemoran en ella son numerosos y de importancia, aunque quedan relegados a un segundo lugar tras la trascendencia espiritual de la laylat al-qadr o noche del poder, noche de paz, como señala la sūra XCVII, en la que el Corán descendió a la tierra y en la que los ángeles descienden también todos los años.

Precisamente al lado de la mención de la noche del poder introduce el Mancebo de Arévalo un pasaje particular en tanto en cuanto está relacionado con un asunto que no suele ser de frecuente asalto en los textos moriscos, la conversión religiosa:

Y si acaso algún infiel retornara enta el adin esti, cuando sia conoçida su seguranza, fádenlo y denle todos el parabién y ónrenlo; esti no dará cuenta de su pura mortificança, porque naçió del muerto sin engendramiento ḩ alel. Y, por eso, será en graçia reçién naçido.

Llama la atención el uso del primer verbo, “retornar”. Sólo se retorna desde donde una vez se ha ido, y si aceptamos que el "adīn” (= ad-dīn, religión, normalmente islámica) se refiere al islam, nos encontramos con la posibilidad de que alguien que dejó esta religión pueda volver a ella. Cuando se esté seguro de la sinceridad de su conversión, ha de ser aceptado sin problemas dentro de la comunidad. Hasta ahora el texto no parece presentar muchos problemas y, de hecho, ese nacer de un muerto sin “engendramiento halāl” p odría referirse al nacimiento de una persona fuera de la comunidad islámica. Ahora bien, señala el texto, ese convertido es considerado un “recién nacido” a la gracia (de Dios, es de suponer) que, de hecho, ha de pasar por el ritual de nacimiento de las fadas. ¿Supone esto una visión islámica? ¿Es la conversión al islam -que implica simplemente la pureza de intención y la pronunciación de la šahāda- realmente una anulación de toda la vida anterior? ¿No responde el texto más bien a la visión judía del converso, para la que toda la vida anterior del que se convierte al judaísmo es como si no existiera? Así lo señala el Talmud (Yebanot, 22ª): “El converso se asemeja a un recién nacido"61.

Otra cuestión, además, se desprende de la inclusión de este fragmento en el calendario del Mancebo que, por supuesto, no encuentra paralelo en otros textos aljamiados semejantes: ¿Por qué la preocupación del Mancebo por la conversión? ¿Por qué un texto tendente a asegurar la buena recep ción del nuevamente convertido en la comunidad? Quizá, de forma tangencial, el

60. “ “ Ramaḍān”, E.I. ${ }^{2}$, VIII, 1994 (M. P LESSNER).

61. Ver M. Orfali, “ La cuestión de la identidad judía en el Maamar ha-Anusim (tratado sobre los conversos forzados) de RaSh-BaSh”, en: J.M. Soto RÁBAnos (ed.), Pensamiento Medieval Hispano. Homenaje a Horacio Santiago-Otero, Madrid, 1988, vol. II, pp. 1267-1288. 
Mancebo está aludiendo, como ha planteado María Jesús Rubiera Mata, a su propia condición de recién convertido al islam. No hay que olvidar sus entrevistas con gente experta en la religión, de los que siempre se confiesa aprendiz, sus fluidos contactos con cristianos y con judíos, y, sobre todo, la observación del alfaquí navarro Ibrāhīm de Reminjo ${ }^{62}$ de que la madre del Mancebo fue cristiana durante veinticinco años. ¿Sería éste uno de los primeros textos que compuso el Mancebo en Aragón, su, digamos, presentación ante los mudéjares-moriscos aragoneses antes de componer obras de may or enjundia y responsabilidad?

Dūu-l-hị̂ŷāa, el último mes del año lunar musulmán, es también elúltimo en ocupar algo de espacio en el discurso cronológico del Mancebo de Arévalo, tras el poco ámbito otorgado a Šawwāl y $\underline{\text { Du}}$-l-qacda. Los ritos alimentarios y la limosna ocupan un papel primordial en este mes en el que tiene lugar la Pascua del Carnero; los ritos que rodean la manipulación correcta de los alimentos que se han de tomar y el carácter voluntario de la limosna (atestiguado por 'Umar Bey) que es realmente meritoria delante de Dios son las directrices fundamentales que ocupan estos días que cierran el año. La expresión final del Mancebo es hacer un llamamiento último a cumplir con la voluntad de Dios expresada en su definitiva revelación islámica: el “profético decir” ha quedado clausurado de manera que en el calendario lunar el musulmán ha de encontrar la expresión definitiva de sus obligaciones regulares como creyente.

Son éstas las líneas fundamentales del calendario islámico escrito por el Mancebo de Arévalo. El autor castellano, como hiciera con el compendio legal del muftí de Segovia Īsā ibn Ŷābir, aprovecha un texto preexistente para ofrecernos su versión particular de la doctrina que se encuentra en él. Como suele suceder con otros textos del Mancebo, la impresión que extrae el lector de él es bastante oscilante: existe un fondo religioso conocido sobre el que el Mancebo opera a su modo particular, mediante la inclusión de un vocabulario peculiarísimo (¿“la predemistanza se nos dejó tuñara”?), unas autoridades islámicas sólo por él conocidas y unas incrustaciones doctrinales al menos sorprendentes. El texto no deja de ser islámico, pero es al tiemp o un poco otras cosas: hay, desde luego, efemérides islámicas que se colocan en su luna correspondiente, pero son incomparablemente menos numerosas que los acontecimientos de la historia religiosa judía (basta comparar el texto con otros calendarios moriscos), por no hablar de la poca proliferación de las fiestas musulmanas; ¿por qué la preocupación en señalar lo que es “de la regla de Ibrāhīm” o lo que dicen las lecciones hebraicas? ¿Es la peculiar mención a la vida completamente nueva del converso una referencia a sus propias circunstancias? Desgraciadamente, el texto del calendario hegiriano no puede ofrecernos respuestas definitivas a esos int errogantes que ya se habían planteado con los textos “mayores” del Mancebo de Arévalo, sino tan sólo unas cuantas ascuas más. Es significativo, creo sin embargo, el hecho de que al lado de esos tremendos manuscritos doctrinales por los que el castellano era conocido

62. Ver L. F. Bernabé Pons, “Nueva hipótesis sobre Baray de Reminŷo”, Sharq Al-Andalus. Estudios Mudéjares y Moriscos, 12 (1995), pp. 299-314. 
exista al menos un texto (p orque no es descartable que pudiera haber más) de reducidas dimensiones y de aplicación eminentemente práctica. Puede que, como decía antes, nos encontremos con un texto temprano del Mancebo, un texto de "prueba" de sus habilidades antes de embarcarse en empresas may ores que dejaran boquiabiertos a sus mecenas aragoneses con su “gran ciencia en el adīn del alislam”.

\section{Transcripción del ms. Aljamiado LXXXII de la Real Academia de la Historia (fols. 94r - 115r) ${ }^{63}$}

[94r.] Bismi illāhi irraḥm āni irraḥ İmi. Esta es la orden y la regla de las lunas por la cuenta de los muslimes y lo que se [94v.] contiene en dicho debdo. La primera luna se diçe almuharram. De esta luna fazen los muçelimes su cuenta. En esta luna fizo Muḥammad aquel tan solene alḥ ầ, que jamás se fizo ni se fará otro más solene, que los caballos y camellos no podían travesar la falla de los caballos. Y aquel año ubo en Maka grande bastura [95r.] y apareçieron señales en munchas partidas que atemorizaron las gentes. Y dixo el sabio de los judíos que se decía Karun: “Oy nos a señalado el Dio gran causa”, y se cayó el ídolo mayor de su tumba. Y dixo el sabio: “Oy somos enfestados, y la predemistanza se nos dexó tuñara”. Y aprés de esto temblaron otros cabildanos estados. El primero de esta luna [95v.] es pascua, día de grande alegría. El terçero de esta luna es día de gran dayuno, y es el primero de los siete días alfadi ilosos. Su ivantalla de esti día es fazer diez arrak ${ }^{\mathrm{c}}$ as de as.s.ala con alḥamdu y sabaḥisma ${ }^{64}$ (sic). Y quien no sepa esta assura faga con lo que sabrá, mas no ganará tanto de su alfadila. Y esta ivantalla se gana antes de as. s.ala [96r.] de az̧zuhar. Y el noveno, deçeno y onçeno es pascua de Atuçe, entre los muçelimes muy solenizada. El deçeno es el día de ${ }^{\mathrm{C}} \mathrm{A}$ ššūra ${ }^{65}$, día de grande dayuno y de mayor alfaḍilla. Esti día ay çincuenta arrak ${ }^{\mathrm{c}} a s$, con veitiçinco assalemes con alḥamdu y diez veçes qul huwa ${ }^{66}$, desde asubḥi fasta el as.s. ala de alcas.s.ar. Esti día a quien no lo abrá supido o por descuido abrá [96v.] comido, pues deténgase y no coma, y ganará su alfaḍḍila. En cualquiere estado que lo tome faga como mejor pueda la (a)bstinençia ${ }^{67}$ : aunque sía enfermo non pesen las meleçinas, y el encarçelado tome la devoçi ón como mejor pueda y ganará como los propios dayunantes. Y quien dexe este día a sabiendas, no ganará su alfaḍila, aunque dayune cuarenta años, porque [97r.] dixo Allāh a Muçe, 'llm,: "Ye Muçe, no vos doy las alfaḍilas de los días alfaḍilosos antes ni después, sino en sus mesmos días y noches”. Esti día crió Allāh todas las cosas más eçelentes; esti día crio los elementos y el alkursī; esti día crió Allāh el sol y la luna y las estrellas; esti día consignó Allāh los signos y planetas; esti día crió Allāh la mar y la serra debajo [97v.] de su mandamiento y obedençia; esti día crió Allāh los çielos y las tierras; esti día crió Allāh a Eddam, y subió a Idris en lugar alto, y libró a

63. He procurado realizar una transcripción que aúne la fidelidad al texto con la legibilidad de la edición. Como es as unto arduo y debatido la forma de conseguir ambos objetivos, quiero indicar que para mi versión me he basado, aunque con algunas excepciones, en los criterios expuestos por Ana Labarta en su Libro de los dichos maravillosos, Madrid, 1993.

64. Ver Corán LXXXVII, 1.

65. Parece existir un error del copista en el manuscrito, puesto que se lee con claridad ${ }^{c} A w h r$ ššura, que se corrige en la presente edición.

66. Ver Corán CXII.

67. En ms. lawstinencia. 
Ibrāhīm del fuego de Namerut. Esti día fue Ayūb remediado de sus congojos; esti día fue venido Aljadir; esti día escribió Allāh el At.aurati; esti día por mandamiento de Allāh corrió el alqalam sobre lo que es nuestro honrado [98r.] Alqur’ān; esti día crió Allah alŷanna gloriosa y comenzó a pesar Firauna. Este día se asentó la safina entre las dos montañas, adonde fue la voluntad de Allāh. Esti día desapareçió 'Içe, ' $l m$, y lo subió Allāh a los çielos. De esti día salió Yūsufde la çisterna y lo perdonó Allāh; esti día reçibió Allāh la repintençia de Eddam; esti día naçió Saliḥ el prudente; esti día salió Yūnus del vientre de la ballena y oyó Allāh a Zakariye: y le dio Allah tal fijo que su estada dotomó tantos justos. Esti día lo visitó 'Içe su primo. Esti día turbó la vista sobre Tobías y fue librado el pueblo de Israel de la cautividad de Firacūn. Esti día fue socorrida Yaçira y [re?]mediado Danie’il en el lago de los leones. Esti día fizo Allāh otros inumerables fechos [99r.] que fazen grandes espandios en las leçiones arábigas y hebraicas, porque fue la regla de Ibrahīm. Esti día no habla de los que fueron de la liña de Ismecīl ni de sus deçendientes, porque fue akebdeçido sobre Isḥāq por el ediamento de Ibr āh $\mathbf{1} m$ y no tocó a los s.ihabes. Esti debdo, aunque corremos tras de su alfạila, es porque Muḥammad lo tomó en devoçión; y quien ganará [99v.] esta alfą̣ ila abrá por ello muncho descanso el día de el juiçio. Treçeno y catorçeno y quinçeno de cada luna son días de grande alfą̣ila. Estos días engrandeçen muncho los arábigos por la greu de los comedios lunares. Diçe 'Umar Bey que estos días de medio de cada luna, aunque no se dayunen se gana muncho en xubelarlos con devoçión, pues quien los dayunará alcanzará grande sombra [100r.] para el día del juiçio, y ansí mismo estos días atarán la rraḥma de Allāh, y quien dayunará todos los corrientes alfadi ilosos aquellos que son de graçia. Esto dixo la Mora de Úbeda: que era sali h i ya dotomada, quiere deçir obra santa, y por eso dixo "Umar Bey: "no á jaleqado que no lleve la alŷanna a su mano derecha”, pues todo muslim ataña sobre los días alfạ̣ilosos, y aunque no los dayune, guarde su [100 v.] acato y faga reverençia sobre ellos con amḥ aos, as.s.adaqas o tasbiḥes, o, si quiere, con dar un dátil en nombre de tal día y de su bendición. Y faga un corte, por sutil que sía, entre uno y otro día, ansí en detenerse de pecar como en bien obrar, porque ansí como xubela la obra en tales días, ansí mismo son los pecados más graves, y por tanto yerran los que diçen: [101r.] “Ya soy en abasto, pues sé fazer as.sala y sé como tengo de dayunar Ramaḍ ān, y entiendo el pro ‘o”, y no curan de los otros resbaladeros; pues ansí pecarán en esta parte los incrueños como los naḥues. Y por es o dixo la Mora de Úbeda: “Cuántas dolençias ay que duelen por no ser entendidas, y cuántas meritanzas se afuellan por no ser conoçidas”. El sagero de esta luna ay repreensión de aniya, [101 v.] quiere decir que somuevas tu palahi iya enta tu Criador, porque su graçia nos ayuda a soportar nuestra pasibilidad en alaydas de paz y amorío. Ansí como nos dio parçida el día y días de el buen prinçipio del año nos dará de su graçia invocando su divina inmensidad.

La segunda luna se dice Șaffar. En esta luna no a días alfạ̣ilosos. [102 r.] Es luna de conquista y, por tanto, no se deben adormeçer los buenos muçelimes, porque en esta luna fueron los s.ihabes vençedores en aquella famosa batalla de Badri y debemos los muçelimes dar loores a nuestro grande y poderoso Allah, señor de los mundos y de sus arriskes y abitadores. Y no menos reverençia fazen en esta luna los días blancos, lunes y alḥ amises.

[102 v.] La tercera luna se dice Rabicu ileguel. El doçeno de esta luna es día muy señalado porque esti día naçió nuestro annabī y es día de grande alegría, y fazen los muçelimes esti día as.sala sobre el advenimiento de Muḥammad. Es dicado como las pascuas y ase de perdonar toda injuria. Y pasado esti día entrarán los días blancos, que son de gran meritanza para redimir pecados.

[103 r.] La cuarta luna se dice $\operatorname{Rabi}^{\mathrm{c}} \mathrm{u}$ elajar. En esta luna no á días de conto, salvo los días blancos, que son treçeno y catorçeno y quinçeno. En esta luna naçió Adulqarnayni. 
La quinta luna se dize Ŷumadi ileguel. Esta luna no trae días señalados.

La seysena luna se dize Ŷumadi ilajar: no á días de conto.

La setena luna se dize Raŷab. El día terçero de esta luna es día de gran dayuno, y es de los siete del año y en graçia espeçialado entre los siete del año, porque este día deçendió sobre Muḥammad la primera aleya de nuestro onrado Alqur' en. Esta luna es dicada al nombre de Allāh tacala. Y quien dayunará esta luna Allāh pondrá su fecho en alluḥ muy señalado, y dará por ello descanso el día [104 r.] del juiçio. El dayuno de esta luna es tanto como dayunar días, años, de los días que no á alfaḍilas. Esti día es que cumplió Allāh todo lo profetizado. Esti día envió Allah a Ŷibrīl sobre Muhammad con el albriçiamiento que fue el annubua de verdad. Esti día perdonó Allāh a todos los annabíes, aquéllos que trajeron annubuas de verdad. Dice Allāh: “Yo daré a los dayunantes de la luna [105 r.] Raŷab tres ivantallas”. La primera, que les perdonará todos sus pecados; la segunda, les dará esfuerzo de creyença; la terçera, que no abrán sed el día del juiçio. Pues ¿cuál de los creyentes dejará esta ivantalla? Tabién ay en esta luna otro día de tan grande alfaçila que si los muçelimes supiesen todo su gualardón, aún abrían menos temoranza: y es el vintiseteno. A esti día [105 r.] no a igual comparanza ni con alḥurrar cativos. Dixo c Umar Bey: “Treinta días como esti, vintiseno son como un alḥ aÿ”. Esti día facen los ŷafawíes grande solenidad por la bendiçión de un rey que fue muy dotomado, que naçió tal día y fue de grande conquista. Dicen los nah ues que nadi faze por su divina bondad, salvo los dayunantes de Raŷab, que es un egsordio su fecho de mayor punto que todos los [105 v.] otros fechos. Porque decir que Raŷab que es mes de Allāh, yo no sé qué mejor retumbo puede sonar ni qué mayor sílaba puede deçender a nos que decir obra dicada de parte de Allāh en espeçialidad a nos encomendada para nuestro bien. Pues quien será causa de conduelma ajena, pues apláquela o demande perdón, porque los tales causadores se alejan de la raḥ ma de Allāh, y ansí mismo los almalakes se apartan de donde no a arraḥma. Pues [106 r.] sia a todos encomendado alto bien a loor y graçia de su divinal amorío, pues ¿quién lo reponará esti bien?, ¿quién no se antepone a bien tan alto?; que Allah a todos nos jaleqó para alŷanna si acoseguimos a sus divinos mandamientos.

La ochena luna se dice $\mathrm{Xa}^{\mathrm{c}} \mathrm{aben}$. Esta luna es dicada al nombre de nuestro annabī, y es luna de grande ivantalla para quien dayunara su estada. [106 v.] Y la noche de medio de esta luna es noche de grande alfạ̣ila, y quien se t.aharará esta noche es su t.ahor tan abastante que aguarda su ivantalla fasta otra noche semejante, en tal que no se pierda por asine o abto desonesto. Y con esta ivantalla and ará nuestra pasibilidad muy segurada por casos contreytos de muertes supitadas. Esta noche, después de alcakmma, ay çien $\operatorname{arrak}^{c}$ as de as.s.ala con una vez alḥamdu y diez veces qul huwa Allāhu [107 r.] aḥadu y çincuenta assalemes. Y entre los assalemes demandarán perdón ada All āh con algunas atakbiras. Esta noche algunos la llaman noche de Tahor: y esto no se dixo por el nombre de tal noche, porque su nombre es la noche de graçia, o como dizen noche de bendiçión, que este dicho no se dixo sino a fin de que nadie çese de t.aharase $\mathrm{e}^{68}$ en esta noche $\mathrm{ni}$ aún con su mujer; y si acaso alguno durmiendo o velando [107 v.] traspasare deleite, pues t.ahárese con brevedad antes que salga el alba si querrá gozar de la bendiçión de tal noche.

La novena luna se diçe Ramaḍ ḍ en onrado. Esta luna es debdo sobre todo muçelim que llegue a la edad: los varones a los desiséis años y las fembras a los quinze; de aquí son obligados al dayuno y a la s.s.ala y azake. Y si acaso antes de allegar al dicho tiempo traspasaren deleite durmiendo o velando [108r] pues ya serán obligados a los dichos debdos. Dize All ah: "Yo perdono a todos los dayunantes de Ramad en contritos y açelados”. Más diçe Allāh: “A Mí no me faze nigún daño el que no dayuna Ramaḍ ḍ en, porque

68. Lectura dudosa; en el manuscrito: “ nadi çese de sat.aharase”. 
es mayor el gualardón de esta luna que toda la nombradía de tierra y mar, porque en esta luna deballa Allāh su gracia con su poderío sobre su alkursī y sobre los de la (a)lumma de creyença. El segundo de esta luna deçendió la potestad [108 v.] soberana sobre Muhammad, s. ${ }^{c} \mathrm{~m}$. El terçero de esta luna conoçió Eddam su pecado. Y el cuarto día se arrepintió Dewud de su pecado, y fizo aquella tan eminente alkafara y lo perdonó All āh. El quinto día naçió Ibrāhīm, calayhi issal ām. El sexto de esta luna fue elegido Sulaymen por rey de los de Ban̄i (I)sra' $1 a^{69}$, que los cristianos dicen los irraelitas. El seteno día nació Yūsuf, fijo de Ya'qub. Esti mismo día tornó la vista sobre Tobías, y el ocheno [108 r.] cayó la libertad sobre los de Bani (I)sra’’̄la. El noveno naçió 'Içe, 'alayhi assalem. El deçeno cayó la reprueba sobre Ayūb y lo destruyó la fortuna. Y esti mismo día se tragó la mar a Fira’na (sic) y fueron libres los de Bani (I)sra’̄ila. El doçeno de esta luna murió Maryam y fue dotada de gracia. El catorcçen o deçendió la graçia sobre Dania’il. Y esti mismo día subió Idrīs al çielo. Y esti día nació Yunus, y esti día perdonó All āh [108v.] a su compaña. Y esti día juntó All āh a Yūsuf con sus hermanos. Y esti día falló Is $m \bar{a}^{\mathrm{c}} \overline{1} l$ el agua de Zamzam. Y en esti día fueron presentados en el alŷanna Edamy Haw ā. En esti día enchó ${ }^{70}$ All āh a Ŷibrīl sobre los de la siḥ āba, que eran en grande aprieto. Y a los vintidós de esta luna deçendió sobre Dewūd el Azzabur. Y esti día nació Suleymen. Y esti día fue consolado 'Içe [109 r.] con la mesa abastada del cielo porque no lo querían creer. A los veitiçinco de esta luna fue dado a Muçe el Țaurat, escribto por la mano de Allah tacalā. Y el vintiseyseno de esta luna envió All āh sobre sus annabíes doçe graçias soberanas, como se dirá en su lugar. Y la noche veitisetena deballó Allah la más alta de las gracias que All āh mostró a los fijos de Eddam. Al vintiseteno [109 v.] deballó All āh la graçia sobre los animales, y a los veytiocho bajó la graçia sobre las aves y cayó la lluvia sobre ellas. Y cuando verán la luna para tomar la pascua farán la dispidiçión con trenta arraka $^{c}$ as de as.s.ala, con quinçe asalemes, y esto antes que salga el sol. Y es amado esdeyunar aprés de salido el sol, porque fasta aquella ora es amado atasbiḥ ar esta Pascua. Estos tres [110 r.] días no se pueden dayunar por devoçión, porque ya los afranqueçió Allah para gozo y alegría. Es debdo pagar la alfit.ra por todos los aminsionados o por los acoseguidos la tal noche si pascuaron en dicha casa y an cumplido sus as.s.alaes; de otra manera no se debe pagar por los tales sovenientes, salvo si fue viandante que lo desayunó por caridad y pasa con su conduelma; [110 v.] aquí no a aplicación costreñida. Y quien traspasa la Pascua con mala fasegada eche cuenta que no fue pascuante y no gozará una trentagésima parte de la alfaḍ ḍila de Ramaḍ ḍ en onrado. Y si acaso algún infiel retornara enta el adīn esti, cuando sia conocida su seguranza, fádenlo y denle todos el parabién y ónrenlo; esti no dará cuenta de su pura ${ }^{71}$ mortificança, porque naçió del muerto sin engen- [110 r] -dramiento ḩalā̄. Y, por eso, será en graçia reçién naçido. Y la noche de Laylati ilqadri ay çien arracÿas con çincuenta assalemes, y ase de leer en cada una vez alḥamdu li-l-Lāhi y diez veçes ina anzzalnahu. Y quien no se presente esta noche en el as.s.ala no le recibe All ah su dayuno. Y ansí mesmo, a quien no paga la alfi ț ra la mañana de Pascua ni a quien no perdona, ni a quien comió o bebió lo ha aramo faze açine, o convida [111 v.] o es convidado del infiel.

La deçena luna se dice Šawel. El primero de esta luna es Pascua de Ramaḍ ḍ en. Esta pascua es tres días y es pascua de alegría.

La oncena luna se dice Dul Qa`īda. El veintiçinqueno de esta luna es de los siete días del año. Es

69. En el manuscrito “ Bani Sara’ìla”.

70. En ms. “enyó”.

71. Lectura hipotética. 
día de grande alfaḍ ḍila para quien lo dayunará. [112 r.] La obra de estos siete días será en carta de claredad para el día de el juiçio, que será día de grandes trebulaçiones y espantos de grande temeridad.

La doçena luna se dice Du alḥiŷati. En esta luna hay nueve días de grande alfaḍ ḍila. No son de preçepto porque son de la regla de Ibrāhīm, [112v.] c $l m$, que antes de la deballaçión de nuestro onrado Alquren eran de preçepto para los judíos, y nuestro annabī Muḥammad tomólos en devoçión y dayunábalos (...) ${ }^{72}$ cada año en esta luna y dejólos encomendados por su grande alfaḍ ḍila. Y el noveno de esta luna es el día de cArafay y es el sagero de los siete nombrados. Y quien no dayuna esti día, no aparta de alfạ̣ ḍila [113 r.] de esti alḥ aŷ, que es alḥ aŷ para los que an poca pasibilidad. El deçeno de esta luna es Pascua de carnero y son cuatro días. Los tres días primeros son de la degüella, que en ellos es reçebido el culu, quiere dezir la degüella del aḍ ḍah aya, que está obligado todo muçelimpoderoso matar un carnero que aya de dos años arriba sin tacha ninguna. Y quien no abrá poder, degüelle lo que podrá [113 v.] de los muchos. Y no seá de salar la carne ni dar a los perros, ni a los infieles ni a los malos muçelimes, ni dejarla osmar, porque todo lo que se dica enta Allāh á de ser preclaro, quiere decir que no á de aber cosa asada ni corrutible, toda á de ser tetidad fasta mirarlo con los ojos. Y anse de matar estas aḍ aḥ ayas con alguaḍ ḍo, y a maharan las pieles para lo que querrán, y no las vendan a los infieles [114 r.] ni las fagan calzados. Alḥ asan no comía la carne de las aḍ ḍaḥ ayas con sal porque dezía que la sal a toda cosa perjudicaba. Y el socorro más amado enta Allāh, y el que más Allāh lo estima, es aquél que favoreçe con tal fecho, como la ḍaḥaya. Dize 'Umar Bey que la s.s.adaqa que se faze para la onor de los días dicados, esta as.s.adaqa no es del número as.s.adaqoso. Dize All āh tacale: “Ansí [114v.] será como la montaña ençima de los montes”. cA bū (sic) Bakrī con pan y dátiles onró la Pascua por socorrer a los pobres de Qurayxi. Dixo el annabī Muḥ ammad, s. ${ }^{\mathrm{c}} m$ : “Ama All āh al franco y aborreçe al escaso, y dobla sus arrisques a quien es su voluntad”; o como se vee acá en el suelo: los secretos de All āh son muy alejados de nos, mas aún los alcanzarán aquéllos que farán nuevas obras [115 r.] con los preçeptos que nos encomendó All ăh. Y no vaya nadi aprés de los fechos de Allāh; cada uno siga los mandamientos de All $\bar{a}$, porque todo lo que a de acaeçer es ada All āh solo; y peca quien va tras de otras adevinanzas, porque ya se atancó el profético dezir, porque los tales caen en préstamos muy cavernosos y aborridos de su divina bondad.

\section{RESUMEN}

Edición y estudio de un texto manuscrito del Mancebo de Arévalo que contiene un calendario islámico. El texto va pasando revista a todos los meses lunares, indicando los días de mayor piedad y virtud, recomendando actos rituales y mostrando las conmemoraciones histórico-religiosas que se celebran dichos días. Pese a su carácter normativo, en el que no hay mucho lugar para la originalidad, el texto trasluce los rastros especiales de la mano de este original autor castellano.

\section{ABSTRACT}

Edition and study of a manuscript of the 'Mancebo de Arévalo' containing an islamic calendar. The text revises lunar months, indicating days of special piety and virtue, recommending ritual ceremonies, and remembering their historical and religious

72. Hay una palabra mal escrita que se monta sobre la siguiente que hace muy difícil la lectura. 
commemorations. In spite of its preceptive nature, with no much place to originality, the texts shows the special traces of this outstanding castilian writer. 